\title{
Investigating the effects of appropriate fitting footwear on functional performance level, balance and fear of falling in older adults: A comparative-observational study
}

\author{
Tuba Maden, PhD, PT*, Kezban Bayramlar, Prof., PT, Cagtay Maden, PhD, PT, \\ Yavuz Yakut, Prof., PT
}

Hasan Kalyoncu University, Faculty of Health Sciences, Gaziantep, Turkey

\section{A R T I C L E I N F O}

\section{Article history:}

Received 20 October 2020

Received in revised form 1 January 2021

Accepted 5 January 2021

Available online $\mathrm{xxx}$

\section{Keywords:}

Aged

Accidental Falls

Postural balance

Shoes

Physical Functional Performance

\begin{abstract}
A B S T R A C T
The aim of the study was to assess the characteristics of footwear altogether and to compare the effect of appropriate-fitting and ill-fitting footwear on functional performance, balance, and fear of falling (FoF) in older adults. Individuals who wore appropriate-fitting $(n=61)$ or ill-fitting footwear $(n=92)$ were enrolled in the study. Footwear was evaluated using the Footwear Assessment Scale (FAS). The participants were assessed using the Berg Balance Scale (BBS) for balance, the Timed Up and Go test for functional performance and the Activities-specific Balance Confidence scale for FoF. Tests were conducted twice for each individual with or without footwear. Differences between the groups were analyzed using the MANOVA for scores of balance, performance and fear of falling and Chi-squared test for homogeneity. The Paired t-test was used to compare test scores with or without footwear. It was concluded that appropriate-fitting footwear improves balance, reduces fear of falling and may affect functional performance positively.

ClinicalTrials.gov No: NCT04151654
\end{abstract}

(c) 2021 Elsevier Inc. All rights reserved.

\section{Introduction}

Footwear is an essential component of foot health and its function is to protect the feet against external elements and. ${ }^{1}$ The structure and biomechanics of the foot change during the aging process and are affected by the presence of foot conditions, pain, deformities, disability, balance and gait disorders. ${ }^{2}$ Several systemic diseases such as diabetes mellitus, high blood pressure, obesity, osteoporosis and arthritis cause foot problems and deformities. ${ }^{2}$ Foot disorders have been reported in $71 \%$ to $87 \%$ of older adults, making foot care and health an important part of public health. ${ }^{2}$ Wearing properly fitting shoes both supports the management of foot disorders and maintains foot health.

Appropriate-fitting footwear should enhance friction, increase the stability of the foot, provide shock absorption, and have therapeutic features for foot deformities. ${ }^{1}$ An appropriately fitting footwear has the correct size, proper material for the upper and sole, provides stability and prevents slips, and a toe box that relieves pressure on the toe. ${ }^{1,3,4}$ Ill-fitting footwear can lead to functional limitations, falls, impaired walking mobility, and foot pain. ${ }^{5}$ Furthermore, ill-fitting

\footnotetext{
* Correspond authors.

E-mail addresses: tuba.kaplan@hku.edu.tr, tuba.kmaden@gmail.com (T. Maden), kezban.bayramlar@hku.edu.tr (K. Bayramlar), cagtay.maden@hku.edu.tr (C. Maden), yyakut@yahoo.com (Y. Yakut).
}

footwear alters the pressure distribution between the feet, causing imbalance. All of aforementioned factors can severely affect quality of life of the individuals, and their independence in performing the activities of daily living. ${ }^{5}$

Appropriate-fitting footwear has an even more important impact in older adults with balance disorders and a history of falls. Age-related changes in sensory processing (visual, somatosensory, vestibular) and motor control mechanisms (muscle strength, decreased flexibility) and specific footwear characteristics (e.g., shoe type, heel counter, heel height, sole rigidity) have an effect on balance and falls in the older adults. ${ }^{6}$

Balance and falls in older adults has been investigated according to the type of footwear by many researchers. ${ }^{6}$ It has been reported that the types of footwear providing stability for the feet have a positive effect on prevention of falls. ${ }^{6}$ There are many studies examining the impact of footwear characteristics such as sole, heel height, shoe size (length and width) on postural stability and gait in older adults. ${ }^{1,7,8}$ The hardness of the sole influences awareness of foot position, which is related to stability and balance. ${ }^{9}$ However, these studies have not assessed all features of properly fitting footwear and focused only on a particular aspect. ${ }^{1,7,8}$ Moreover, the subjects used a different footwear than their habitual footwear in these studies. Appropriate fitting footwear is dependent on many factors including proper length, heel height, sole hardness and width, toe box, heel cup, arch support, and heel counter stiffness. ${ }^{9}$ There are only a few studies that examined all properties of appropriate fitting footwear. ${ }^{10,11}$ 
In light of these data, the suitability of footwear should be evaluated in older adults, taking into account all aspects of the footwear. Appropriate-fitting footwear should be considered as part of preventive health approaches and rehabilitation. Therefore, the aim of the current study was to assess the impact of footwear on functional performance, balance and fear of falling in older adults, by comparing individuals wearing appropriate-fitting or ill-fitting shoes, taking into account all characteristics of the footwear. The hypothesis is that appropriate-fitting footwear increases functional performance and balance, and decreases fear of falling in older adults.

\section{Materials and method}

\section{Study design and randomization}

This was a comparative observational, single-blind study. The study statistician was blinded to the group allocation of the subjects (i.e. the group with appropriate-fitting footwear and the group with ill-fitting footwear). The individuals who agreed to participate in the study signed informed consent. Block randomization was used for the order of the tests to be performed with or without footwear.

\section{Ethics}

Approval for the study was obtained from Hasan Kalyoncu University, Ethics Committee for Non-invasive Research on 12/04/2016 (No: 2016-06). The study was conducted in the Geriatric Outpatient Clinic of Gaziantep University, Research and Practice Hospital between April 2016 and September 2016.

\section{Study subjects}

The study inclusion criteria were age 65 years or older, being able to perform the balance and functional tests, having no musculoskeletal injury within the last year; and being ambulatory without assistance (i.e. walker, cane, with one person). Individuals with a history of psychiatric, neurological or cognitive disease, a diagnosed condition that could account for possible imbalance and falls, vision or hearing problems, communication difficulties, inability to understand and act on study-related instructions or diabetic foot were excluded.

As shown in Fig. 1, 303 older adults presenting to our clinic were asked whether they wished to participate in the study. Of them, 135 patients did not consent and were excluded. Remaining 168 patients were screened for eligibility. A total of 15 patients were ineligible, including 5 patients with neurological disorders, 7 patients with communication difficulties and 3 patients with diabetic foot and excluded from the study. Thus, the study sample consisted of 153 patients.

\section{Test Procedure}

For all subjects, balance and functional tests were conducted twice, with or without footwear. A 5 min rest was allowed between the tests with or without footwear. The subjects were unshod during the no-footwear test. Half of the participants carried out the test first with footwear and then without footwear. The remaining half of individuals followed the reverse order. This was done to eliminate the learning effect in the tests and randomization was used to allocate individuals to each test group.

Footwear of the participants was assessed using the Footwear Assessment Scale (FAS). Individuals were divided into the "Appropriate-Fitting Footwear Group" (AFG) and the "Ill-Fitting Footwear Group" (IFG) according to FAS results. In the scale development study, the FAS score distribution curve was provided and a score of 12 was reported as the mean value for an appropriate-fitting shoe. ${ }^{12}$ Considering both feet, a score of 22 or below indicated an ill-fitting

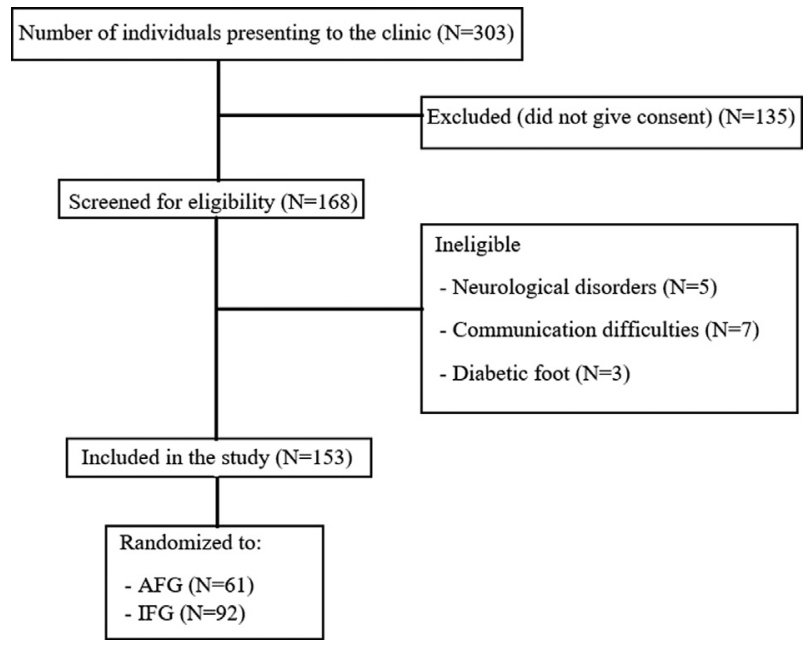

Fig. 1. Study flow chart

footwear. The AFG consisted of individuals who had a FAS score of 23 or above. The block randomization was used to decide which participants were to perform the shoe test first.

\section{Measurements}

\section{General characteristics}

The demographic characteristics of the participants (age, sex, height, body weight, body mass index (BMI)) as well as shoe size and history of falls were recorded. The participants were also asked for how long they have used their shoes (i.e. the shoes they were wearing at the time of presentation) and total duration was recorded in months.

\section{Footwear assessment score}

The Footwear Assessment Score (FAS) was used to assess footwear-related parameters such as the materials and design of the footwear (upper and tread), bending point, width, height of the toe box, getting out of the foot when walking, heel height, footwear style, wearing of the heel, and the distance between the longest toe and the end of the shoe. The score obtained from the FAS scale indicates the suitability level of the footwear and a score of 30 represents the highest suitability level. ${ }^{4,13,14}$ The Turkish version of the FAS was shown to be valid and reliable. The test's ICC for intra- and interobserver reliability was 0.98 and 0.92 , respectively. ${ }^{13}$

An appropriate-fitting footwear has a leather upper material that provides comfort, durability, breathability, and ability to prevent fungal growth features (1 score). The rubber material is suitable for the sole (3 scores). The footwear should hinge at the first metatarsophalangeal joint level (1 score). The width of footwear and the height of the toe box should be appropriate, so that there is no pressure exerted on the toes (2 scores). Footwear should indicate a good fit with no slip during gait (1 score). The difference in the height of the heel and forefoot of the outsole should be less than $25 \mathrm{~mm}$ (1 score). The style of footwear is important to prevent sliding. Shoes and boots with straps, Velcro or laces provide good fixation (3 scores); slip-on boots provide lower fixation (2 scores); moccasins without straps, slippers, backless slippers provide no fixation (0 score). The amount of wear should be less than $5 \mathrm{~mm}$ (1 score). Foot length should be in accordance with footwear length. The difference in length of the foot and footwear should be between $10 \mathrm{~mm}$ and $20 \mathrm{~mm}$ (2 scores). FAS was performed at noon to minimize the effect of volume changes that might occur in the foot during the day on the results.

\section{Assessment of Functional Performance and Balance}

The Timed Up and Go test (TUG) is used for assessment of mobility, balance, walking ability and fall risk particularly in older adults. ${ }^{15}$ 
The TUG is a valid and reliable test for evaluation of functional performance since it involves most activities of daily living. For this test, the participants were asked to stand from a sitting position, walk $3 \mathrm{~m}$, turn back and sit back on to the chair again. The TUG was performed twice for each participant, with or without footwear and the scores were assigned based on the duration of performance (in seconds): normal balance (up to $12 \mathrm{~s}$ ), good balance (up to $10 \mathrm{~s}$ ), impaired balance (11-20 s), impaired balance-low risk of falling (11-20 s), and high risk of falling (longer than $20 \mathrm{~s}$ ). ${ }^{16}$ The TUG test has shown high inter-rater reliability (ICC $=0.99$ ) and high intra-rater reliability $($ ICC $=0.99)$ in a sample of community-dwelling older adults. ${ }^{15}$

The Berg Balance Scale (BBS) is used to assess the ability of the participants to maintain their balance when performing functional activities. ${ }^{17}$ Maintaining balance becomes more difficult with smaller base of supports. The BBS was used to evaluate the ability of the participants to safely balance during a series of tasks including sitting unsupported, sitto-stand movement, turning, and retrieving objects from the floor (14 items). A BBS score of 0 and 4 points for each variable assessed represents safe and independent execution of assigned tasks (normal performance), and unsafe and dependent execution of assigned tasks (unable to perform a task), respectively. Total possible score is ranges from 0 to 56 points. The test was conducted twice for each participant, with or without footwear. The Turkish version of the BBS was used for the study where a cumulative score of 0-20 indicates high risk, 21-40 moderate risk and $41-56$ low risk. ${ }^{18}$ The test's ICC for intra- and inter- observer reliability was 0.98 and 0.97 , respectively. The Chronbach $\alpha$ of the Turkish version of the BBS was $0.98 .{ }^{18}$

\section{Assessment of fear of falling}

Fear of falling is commonly assessed using the Activities-specific Balance Confidence scale $(A B C)$ which can predict the risk of falling. The $A B C$ was used to determine the participants' fear of falling. Each participant rated functional activities that include 16 indoor and outdoor activities o a scale from $0 \%$ (no confidence) to 100\% (complete confidence) representing their subjective confidence about maintaining their balance. In this test, higher scores indicate greater confidence in balance. ${ }^{19}$ The $\mathrm{ABC}$ showed excellent reliability and good validity, and the Cronbach's a coefficient was $0.96 .^{19}$

\section{Statistical Analysis}

The Statistical Package for the Social Sciences version 22.0 software was used for statistical analysis. The $G^{*}$ power analysis was used to estimate the minimum sample size needed. It was found that a sample size of 43 subjects in each group would be needed to achieve $90 \%$ power in relation to TUG, at a type I error rate of 5\% and a type II error rate of $10 \%$ for testing the bilateral hypothesis limits, to provide. ${ }^{20}$ For the descriptive analyses, the frequency in percentage (\%) and mean \pm standard deviation $(X \pm S D)$ of the study variables were presented. Normality of distribution was tested with skewness-kurtosis, histogram plots, and the Kolmogorov-Smirnov test. Chi-square was used to investigate the homogeneity between the "Appropriate-Fitting Footwear" and "Ill-Fitting Footwear" groups with respect to gender and fall history. The Student's t-test was used to check the homogeneity between the study groups for age, BMI, FAS, and total duration of footwear use. The multiple analysis of variance MANOVA was used for comparison of the study groups in functional performance, balance, and fear of falling. The Paired Student's t-test was used to understand how performance was affected when appropriate-fitting or ill-fitting footwear was removed.

\section{Results}

Distribution of individuals' characteristics according to groups and the results of homogeneity between the appropriate-fitting footwear group and the ill-fitting footwear group are shown in Table 1. The
Table 1

Characteristics of study participants.

\begin{tabular}{|c|c|c|c|c|}
\hline Characteristics & $\operatorname{AFG}(\mathrm{N}=61)$ & $\operatorname{IFG}(\mathrm{N}=92)$ & $\mathrm{X}^{2}$ or $\mathrm{t}$ & $p$ \\
\hline Gender & & & 6.87 & $0.00^{\mathrm{a}, * *}$ \\
\hline Female & $20(33 \%)$ & $50(54 \%)$ & & \\
\hline Male & $41(67 \%)$ & $42(46 \%)$ & & \\
\hline Age (years) & $70.19 \pm 5.89$ & $70.46 \pm 4.64$ & 0.31 & $0.75^{\mathrm{b}}$ \\
\hline Body Mass Index $\left(\mathrm{kg} / \mathrm{m}^{2}\right)$ & $27.27 \pm 4.18$ & $27.69 \pm 4.71$ & 0.54 & $0.58^{\mathrm{b}}$ \\
\hline FAS Score & $23.75 \pm 2.31$ & $15.86 \pm 3.51$ & 16.73 & $0.00^{\mathrm{b}, * *}$ \\
\hline $\begin{array}{l}\text { Total duration of footwear } \\
\text { use (months) }\end{array}$ & $12.52 \pm 9.27$ & $13.59 \pm 8.80$ & 0.71 & $0.47^{\mathrm{b}}$ \\
\hline History of Falls & & & 2.19 & $0.23^{\mathrm{a}}$ \\
\hline No & $52(85 \%)$ & $68(74 \%)$ & & \\
\hline $1-2$ in the previous year & $7(12 \%)$ & $17(18 \%)$ & & \\
\hline $\begin{array}{l}\text { More than } 2 \text { in the } \\
\text { previous year }\end{array}$ & $2(3 \%)$ & $7(8 \%)$ & & \\
\hline \multicolumn{5}{|c|}{$\begin{array}{l}\text { Note: } \\
{ }_{* *} p<0.01 \text {; AFG: Appropriate-Fitting Footwear Group, IFG: Ill-Fitting Footweal } \\
\text { Group }\end{array}$} \\
\hline $\begin{array}{l}\text { Group } \\
\text { a } \text { Chi-squared test } \\
\text { b } \text { Student's t-test. }\end{array}$ & & & & \\
\hline
\end{tabular}

number of females was higher in the ill-fitting footwear group $(p<0.05)$. The groups were similar with regard to mean age, BMI, duration of footwear use, and history of falls $(p>0.05)$. Since individuals were divided into appropriate-fitting footwear group and ill-fitting footwear group according to the FAS test, the FAS score was lower in the ill-fitting footwear group than in the appropriate-fitting footwear group ( $p<0.05$ ). 15\% of the appropriate-fitting footwear group and $26 \%$ of the ill-fitting footwear group had a history of falls.

The BBS scores of the appropriate-fitting footwear group scored higher on the BBS than the ill-fitting footwear group, both with or without footwear $(p<0.05)$. However, there was no statistically significant difference between the groups in the TUG scores when tested with or without footwear $(p>0.05)$. The appropriate-fitting footwear group had less fear of falling compared to ill-fitting footwear group based on ABC scores $(p<0.05)$ (Table 2). There were no differences between AFG and IFG in the BBS scores with footwear and BBS scores without footwear (Table 3$)(p>0.005)$. TUG scores with or without footwear were similar in both AFG and IFG $(p>0.005)$.

Table 2

Comparison of groups in balance, functional performance and fear of falling.

\begin{tabular}{lllrl}
\hline & AFG & IFG & \multicolumn{1}{l}{ F } & \multicolumn{1}{l}{$p$} \\
\hline BBSwF (score) & $52.32 \pm 5.51$ & $48.96 \pm 8.10$ & 5.945 & $.016^{*}$ \\
BBSoF (score) & $52.42 \pm 5.50$ & $49.17 \pm 7.87$ & 5.999 & $.016^{*}$ \\
TUGwF(sec) & $10.81 \pm 4.67$ & $12.11 \pm 5.09$ & .492 & .484 \\
TUGoF (sec) & $10.86 \pm 5.21$ & $12.05 \pm 5.94$ & .246 & .621 \\
ABC & $86.28 \pm 14.46$ & $74.36 \pm 24.37$ & 9.930 & $.002^{*}$ \\
\hline
\end{tabular}

Note: AFG: Appropriate-Fitting Footwear Group, IFG: Ill-Fitting Footwear Group, BBSwF: Berg Balance Scale with Footwear, BBSoF: Berg Balance Scale without Footwear, TUGwF: Timed Up and Go with Footwear, TUGoF: Timed Up and Go without Footwear; * $\mathrm{p}<0.05$ indicates significant difference between the groups by MANOVA.

Table 3

Comparison of performance with or without footwear according to groups.

\begin{tabular}{lllll}
\hline & With Footwear & Without Footwear & $\mathrm{t}$ & $p$ \\
\hline AFG-BBS (score) & $52.32 \pm 5.51$ & $52.42 \pm 5.50$ & 1.243 & 0.217 \\
AFG-TUG (sec) & $10.81 \pm 4.67$ & $10.86 \pm 5.21$ & 0.212 & 0.832 \\
IFG-BBS (score) & $48.96 \pm 8.10$ & $49.17 \pm 7.87$ & 0.772 & 0.443 \\
IFG-TUG (sec) & $12.11 \pm 5.09$ & $12.05 \pm 5.94$ & 0.312 & 0.756 \\
\hline
\end{tabular}

Note: AFG-BBS: Berg Balance Scale in Appropriate-Fitting Footwear Group, AFG-TUG: Timed Up and Go test in Appropriate-Fitting Footwear Group, IFG-BBS: Berg Balance Scale in Ill-Fitting Footwear Group, IFG-TUG: Timed Up and Go test in Ill-Fitting Footwear Group; * $p<0.05$ changes within the group by Paired Student's t-test. 


\section{Discussion}

The aim of this study was to investigate the effect of appropriatefitting footwear on functional performance level, balance and fear of falling in older adults. The study determined that individuals with appropriate-fitting footwear had better balance and less fear of falling than individuals with ill-fitting footwear. However, no effect of appropriate-fitting footwear was observed on functional performance. The originality of our study is that all aspects of the footwear were considered and assessments were based on overall scores.

Menant et al. investigated the effect of the heel, heel-collar height, footwear sole feature, and a number of suitable footwear types on balance and postural oscillations, reporting that balance was affected negatively as the heel height increased. ${ }^{21}$ In that study, the impact of footwear on balance was examined by comparing a standard shoe with seven other shoes that differed in one feature only. However, in the current study, we evaluated all parameters related to shoe suitability in different shoes separately. In another study examining all footwear characteristics, women's shoes with high heels and soft soles were found to cause balance problems, leading to falls and fractures. ${ }^{22} \mathrm{~A}$ study reported that use of ill-fitting footwear plays a key role in foot pain and leads to disability and deformities, and that the position and sensory input in the feet affect balance. ${ }^{23}$ Our findings are consistent with those of other studies, which reported that wearing appropriatefitting footwear improved balance in older individuals. Additionally, there are epidemiological studies reporting that foot problems are more common in women and women are twice as likely to have foot pain as men, possibly because of higher incidence of wearing ill-fitting shoes among women. ${ }^{1}$ Consistently, most of the females included in the current study were in the ill-fitting footwear group.

The present study assessed numerous factors affecting footwear suitability in older adults, which were not previously assessed in Turkey. However, there is a need for more comprehensive and multicenter studies in the older adult population, focusing on attitude and knowledge about foot health and footwear and footwear preference. López-López et al. investigated the attitudes and knowledge of older individuals about wearing appropriate footwear and its health benefits. ${ }^{24}$ One study investigated the footwear purchasing habits of older people in Australia ${ }^{25}$ and found that the time between footwear purchases for older adults varied between $1-2$ years. This was consistent with our finding that the participants reported using their shoes for about 1 year. However, further studies are needed to explore footwear purchasing habits, suitability of footwear, and duration of footwear use in older adults in Mediterranean countries, because footwear-purchasing habits can affect suitability of footwear. Longterm use of footwear causes deformations in the footwear, reducing the suitability of the shoe.

There are studies in the literature reporting on the effect of shoe suitability of the individuals wearing different kinds footwear. ${ }^{21,26,27}$ However, the individuals used a different footwear than their habitual footwear or individuals have become accustomed to the test in these studies. In other words, the effect of learning the test was not taken into consideration. Although the suitability of the shoes was different, repeating the same test could have affected the test results and the results may be misleading due to the difference in the shoe fit in the test. For this reason, the authors of the current study believe that they eliminated the effect of learning the test by using a random testing order with or without shoes, representing a different methodology. In addition, the authors think that if older individuals were tested with new shoes, their test performance could be affected. Therefore, the present study differs from others in the relevant literature by carrying out the tests with the footwear that individuals were accustomed to.

Güchan et al. examined the effect of footwear suitability on functional performance in younger individuals. They stated that appropriate-fitting footwear had positive effects on dynamic balance, but not on static balance. ${ }^{11}$ Another study by Aslan, et al. also demonstrated the importance of the selection of appropriate-fitting footwear in balance and functional performance. ${ }^{28}$ Numerous studies have uniformly shown that gait speed changes depending on footwear suitability. 26,27,29,30 Gait speed and step length increased, while step width decreased when different aspects of footwear suitability such as base material, dorsal fixation feature, and footwear upper material were compared. ${ }^{26}$ Footwear with dorsal fixation improved minimum foot clearance compared to slippers and bare feet conditions and less heel slippage than slippers and an increase in double support. ${ }^{26}$ However, some studies reported that the association of shoe characteristics with gait is not clear. ${ }^{27,29}$ One study comparing appropriate-fitting and ill-fitting shoes showed that wearing ill-fitting shoes did not have an effect on TUG scores. ${ }^{30}$ In the present study, it was shown that functional performance did not change according to footwear suitability.

Previously, it has been demonstrated that unsafe and unsuitable shoes play an important role in increasing the risk of falls in older adults. ${ }^{9}$ Ill-fitting footwear such as soft footwear, high heel footwear, and easy slip on and take off shoes increase the risk of falls. ${ }^{6}$ Even though no serious injury is caused, ill-fitting footwear causes loss of confidence, a fear of falling, and a restriction in activity. ${ }^{30}$ Our findings are in line with those reported in the literature in that aspect At the beginning of the study, it was considered that wearing appropriate-fitting footwear reduces the fear of falling in older adults. Consistently, the number of repetitive falls in the last year was less in the group wearing suitable shoes than the other group in our study.

In the studies that compared the results of balance testing of the same individual with or without footwear, postural oscillations were measured with two different slippers and socks worn in the house, and the stability limits of the individuals were determined. These studies showed that more suitable slippers increased balance ability and cadence of the individual. Menz et al. showed that wearing socks resulted in better balance performance but slowed the speed of gait. ${ }^{31}$ Antonio et al. demonstrated that older adults were at greater risk of falling during stair descent at barefoot conditions compared to insole hardness. ${ }^{32}$ Insole hardness and footwear size affect tactile sensation of the foot and this changes balance and functional performance, especially in older adults. ${ }^{32,33}$ Barbara et al showed that appropriate-fitting footwear is better than barefoot for balance in young adults. ${ }^{33}$ Horgan et al determined that the BBS scores with and without footwear were different in older women. ${ }^{10}$ It was shown that footwear characteristics were not associated with changes in the BBS scores, but instead the individual wearing any footwear significantly improved their balance compared to being barefoot. ${ }^{10}$ However, the results of balance testing with or without footwear were similar in the IFG and AFG groups in the present study. Comparing the test results for with and without footwear, the effect of the characteristics of appropriate-fitting footwear was not clearly determined. The test performances were clinically good when ill-fitting footwear was removed in the IFG group, but this difference was not statistically significant.

In light of the results of this study, footwear can affect balance, functional performance and fear of falling in older adults. For this reason, all healthcare providers working with older adults should evaluate suitability of footwear in the clinic. In order to determine whether the footwear is suitable or not, many factors such as material, stability, type and size of the foot should be evaluated altogether instead of evaluating a single variable in research studies.

This study has a number of limitations. Firstly, the age of footwear was not considered and this is a limitation because it can affect suitability. The Footwear Assessment Scale is used in different age groups but there is a need to determine its validity and reliability in older adults. Secondly, gender distribution was different in the two groups. In addition, individuals who had balance problems were not included in the study and this may have limited our ability to investigate the 
effect of appropriate-fitting footwear on balance, functional performance and fear of falling in this group.

The current study demonstrated that appropriate-fitting footwear improves balance and functional performance and reduces fear of falling in older adults. Further studies involving detailed footwear assessments are warranted to clearly show the effects of specific characteristics of footwear on balance, gait and functional performance in older population. Also, studies investigating the attitudes, behaviors and knowledge of older persons about footwear will greatly contribute to the relevant literature. Comprehensive studies can be conducted in older adults to investigate the cause of falls using regression analysis incorporating footwear as a variable. Moreover, the relationship between footwear and healthcare costs due to fallrelated complications (e.g. hip fractures) should also be investigated.

\section{Conclusion}

This study provides evidence on the positive effect of appropriatefitting footwear on balance, functional performance and fear of falling in older adults. Footwear assessment taking into account all aspects of the footwear can be considered as an important approach to reduce fear of falling and improve balance in older adults.

\section{Declaration of Competing Interest}

The Author(s) declare(s) that there is no conflict of interest.

\section{Acknowledgments}

None.

\section{Funding}

None.

\section{Supplementary materials}

Supplementary material associated with this article can be found in the online version at doi:10.1016/j.gerinurse.2021.01.001.

\section{References}

1. López-López D, Expósito-Casabella Y, Losa-Iglesias M, Bengoa-Vallejo RB, Saleta-Canosa JL, Alonso-Tajes F. Impact of shoe size in a sample of elderly individuals. Rev Assoc Med Bras. 2016;62(8):789-794. https://doi.org/10.1590/1806-9282.62.08.789.

2. Rodríguez-Sanz D, Tovaruela-Carrión N, López-López D, et al. Foot disorders in the elderly: a mini-review. Dis Mon. 2018;64(3):64-91. https://doi.org/10.1016/j.disamonth.2017.08.001.

3. Palomo-López P, Becerro-de-Bengoa-Vallejo R, Losa-Iglesias ME, Rodríguez-Sanz D, Calvo-Lobo C, López-López D. Footwear used by older people and a history of hyperkeratotic lesions on the foot: a prospective observational study. Medicine. 2017;96(15):e6623. https://doi.org/10.1097/MD.0000000000006623.

4. Yurt Y, Sener G, Yakut Y. Footwear suitability in Turkish preschool-aged children. Prosthet Orthot Int. 2014;38(3):224-231. https://doi.org/10.1177/0309364613497047.

5. López López D, Losa Iglesias ME, Becerro de Bengoa Vallejo R, et al. Optimal choice of footwear in the elderly population. Geriatr Nurs. 2015;36(6):458-461. https:// doi.org/10.1016/j.gerinurse.2015.07.003.

6. Davis A, Haines T, Williams C. Do footwear styles cause falls or increase falls risk in healthy older adults? a systematic review. Footwear Sci. 2019;11(1):13-23. https:// doi.org/10.1080/19424280.2018.1555861.

7. Losa Iglesias ME, Becerro de Bengoa Vallejo R, Palacios Peña D. Impact of soft and hard insole density on postural stability in older adults. Geriatr Nurs. 2012;33 (4):264-271. https://doi.org/10.1016/j.gerinurse.2012.01.007.
8. Kim DWF J-S, Cha YJ, You JE, Kim K. Effects of different heel heights on plantar foot pressure distribution of older women during walking. J Phys Ther Sci. 2012;24 (12):1091-1094. https://doi.org/10.1589/jpts.24.1091.

9. Jellema A, Huysmans T, Hartholt K, van der Cammen T. Shoe design for older adults: evidence from a systematic review on the elements of optimal footwear. Maturitas. 2019. https://doi.org/10.1016/j.maturitas.2019.06.002.

10. Horgan NF, Crehan F, Bartlett E, et al. The effects of usual footwear on balance amongst elderly women attending a day hospital. Age Ageing. 2009;38(1):62-67. https://doi.org/10.1093/ageing/afn219.

11. Güçhan Z, Eı Özaydınlı, Demirel S, Yüzlü V, Nilgün B. Ayakkabı kullanımı ile ayak deformiteleri, denge ve fonksiyonel performans arasındaki ilișkinin incelenmesi. J Exerc Ther Rehabil. 2014;1(1):3-42.

12. Byrne M, Curran MJ. The development and use of a footwear assessment score in comparing the fit of children's shoes. The Foot. 1998;8(4):215-218.

13. Yakut Y, Yurt Y, Bek N. Reliability of Turkish version of footwear assessment score Turk J Physiother Rehabil. 2010;21(3).

14. Kaplan T, Bayramlar K, Maden Ç, Usgu G, Yakut Y. Yașlı bireylerde ayakkabı uygunluğunun düșme korkusuna olan etkisinin araștırılması. J Exerc Ther Rehabil. 2018;5 (3):167-172.

15. Shumway-Cook A, Brauer S, Woollacott M. Predicting the probability for falls in community-dwelling older adults using the Timed Up \& Go Test. Phys Ther. 2000;80(9):896-903.

16. Bischoff HA, Stähelin HB, Monsch AU, et al. Identifying a cut-off point for normal mobility: a comparison of the timed 'up and go'test in community-dwelling and institutionalised elderly women. Age Ageing. 2003;32(3):315-320.

17. Berg KO, Wood-Dauphinee SL, Williams JI, Maki B. Measuring balance in the elderly: validation of an instrument. C Can J Public Health. 1992;83:S7-S11. https:// doi.org/10.1093/ptj/80.9.896.

18. Sahin F, Yilmaz F, Ozmaden A, Kotevoglu N, Sahin T, Kuran B. Reliability and validity of the Turkish version of the Berg Balance Scale. J Geriatr Phys Ther. 2008;31 (1):32-37. https://doi.org/10.1093/ageing/32.3.315.

19. BÖ Ayhan Ç, N Kirdi, Yavuz YAKUT, GÜLER Çağatay. The Turkish Version Of The Activities Specific Balance Confidence (Abc) scale: its cultural adaptation, validation and reliability in older adults. Turk Geriatri Derg. 2014;17(2):157-163.

20. Valenzuela PL, Maffiuletti NA, Saner H, et al. Isometric strength measures are superior to the timed up and go test for fall prediction in older adults: results from a prospective cohort study. Clin Interv Aging. 2001;2020(15). https://doi.org/10.2147/CIA.S276828.

21. Menant JC, Steele JR, Menz HB, Munro BJ, Lord SR. Effects of footwear features on balance and stepping in older people. Gerontology. 2008;54(1):18-23. https://doi. org/10.1159/000115850.

22. Sherrington C, Menz HB. An evaluation of footwear worn at the time of fall-related hip fracture. Age Ageing. 2003;32(3):310-314. https://doi.org/10.1093/ageing/32.3.310.

23. Woollacott MH, Pei-Fang T. Balance control during walking in the older adult: research and its implications. Phys Ther. 1997;77(6):646. https://doi.org/10.1093/ptj/77.6.646.

24. López-López D, García-Mira R, Palomo-López P, et al. Attitude and knowledge about foot health: a spanish view. Rev Lat Am Enfermagem. 2017;25:e2855. https:// doi.org/10.1590/1518-8345.1643.2855.

25. Munro BJ, JRJJotAPMA Steele. Household-shoe wearing and purchasing habits. a survey of people aged 65 years and older. J Am Podiatr Med Assoc. 1999;89 (10):506-514

26. Davis AM, Galna B, Murphy AT, Williams CM, Haines TP. Effect of footwear on minimum foot clearance, heel slippage and spatiotemporal measures of gait in older women. Gait Posture. 2016;44:43-47. https://doi.org/10.1016/j.gaitpost.2015.11.003.

27. Doi T, Yamaguchi R, Asai T, et al. The effects of shoe fit on gait in community-dwelling older adults. Gait Posture. 2010;32(2):274-278. https://doi.org/10.1016/j.gaitpost.2010.05.012.

28. Aslan UB, Cavlak U, Yagci N, Akdag B. Balance performance, aging and falling: a comparative study based on a Turkish sample. Arch Gerontol Geriatr. 2008;46 (3):283-292. https://doi.org/10.1016/j.archger.2007.05.003.

29. Menant JC, Steele JR, Menz HB, Munro BJ, Lord SR. Effects of walking surfaces and footwear on temporo-spatial gait parameters in young and older people. Gait Posture. 2009;29(3):392-397. https://doi.org/10.1016/j.gaitpost.2008.10.057.

30. O’Rourke B, Walsh M, Brophy R, et al. Does the shoe really fit? characterising ill-fitting footwear among community-dwelling older adults attending geriatric services: an observational cross-sectional study. BMC geriatrics. 2020;20(1):1-8. https://doi.org/10.1186/s12877-020-1448-9.

31. Menz HB, Auhl M, Munteanu SE. Effects of indoor footwear on balance and gait patterns in community-dwelling older women. Gerontology. 2017;63(2):129-136. https://doi.org/10.1159/000448892.

32. Antonio PJ, Perry SD. Quantifying stair gait stability in young and older adults, with modifications to insole hardness. Gait Posture. 2014;40(3):429-434. https://doi. org/10.1016/j.gaitpost.2014.05.009.

33. Smith B, Hartman A, Martin D, Milford J, Simmonds J, Truong C. Young adults performance of unipedal dynamic balance with various footwear conditions. Int J Exerc Sci. 2020;13(4):206-215. 